\title{
A comparative study on the effect of the stress relieving annealing on the residual stress and the properties of 5B70 and 5A06 aluminum alloys
}

\author{
Xiaoyu Shen ${ }^{1, a^{*}}$, Chao Cui ${ }^{1, b}$, Cailing $\mathrm{Li}^{1, \mathrm{c}}$, Zhe Wang ${ }^{1}$, YuLiang Zhang ${ }^{1}$, \\ Xiaoming Lai ${ }^{1}$, Zhanjiao Gao ${ }^{1}$ \\ ${ }^{1}$ Beijing spacecrafts, Beijing,China \\ a xiaoyu.shen@163.com, ${ }^{\text {b }}$ cuichao20012001@163.com, ${ }^{c}$ lindali6@126.com
}

Keywords: 5B70 aluminum alloy; residual stress; stress relieving annealing; mechanical properties Abstract. Different temperature and time parameters were adopted in the stress relieving annealing processes of 5B70 and 5A06 aluminum alloys. Then, the mechanical properties and the variation regularity of residual stress of 5B70 and 5A06 aluminum alloys before and after stress relieving annealing were studied. The results show that after stress relieving annealing, tensile strength and yield strength of 5B70 aluminum alloy decrease. Meanwhile, elongation and contraction ratio of section improve. The removing effect of residual stress is remarkable. Under the same stress relieving annealing process, the performance degradation of 5B70 aluminum alloy is smaller than that of 5A06 aluminum alloy. Finally, the stress relieving annealing schedule of 5B70 aluminum alloy was obtained to be $180 \pm 10^{\circ} \mathrm{C}$ and 1 hour. And the residual stress caused by forming is reduced by $50 \%$.

\section{Introduction}

Compared with the traditional alloys, the aluminum alloy with minor Sc addition (0.07-0.35wt.\%) has the characteristics of high strength, high toughness, excellent corrosion resistance and welding performance, etc. It is a lightweight structure for the new generation spacecraft and aero vehicle. Based on 5A06 aluminum alloy, 5B70 aluminum alloy becomes more toughening by the effect of Sc and $\mathrm{Zr}$ micro alloyed. Compared with the 5A06 aluminum alloy, the tensile strength increases by $20 \%$, the yield strength increases by $40 \%$, and 5B70 aluminum alloy was applied to the panel structures of the spacecraft.

In order to reduce the weight, the structures of the spacecraft always uses the integral structure designs, such as integral panels, integral crossbeams, integral connection frames, reinforced frames, etc. However, the requirements for the new manufacturing technology of the integral structure are urgent. In the development of the product, it is found that many integral panels, frames and thin-wall parts have different degrees of deformation in machining process. Due to the lack of effective suppression of deformation process technology, deformation of the parts cannot be used in the case of the situations. Deformation of the whole structures of the spacecraft often causes huge economic losses during the processing.

Internationally, EADS, Lockheed Martin [1] and other defense contractors has been working on the related research, and points out that the residual stress is the main cause of machining deformation. In order to control the machining deformation, the residual stress level should be controlled firstly. As an effective and convenient method to remove residual stress, the stress relieving method has been widely used in industrial productions.

Therefore, in this paper, the 5B70 aluminum alloy and 5A06 aluminum alloy are compared and analyzed, and the residual stress is measured and analyzed at different temperatures and time. Combined with the results of mechanical property tests, the influence of the stress on the properties of the material and residual stress elimination effect are obtained. Finally, a reasonable stress relieving annealing schedule was formulated. 


\section{Experiment}

5B70 aluminum alloy is provided by Southwest Aluminum Refco Group Ltd, the thickness is 6mm, and the heat treatment state is H32.Mechanical properties test references GB/T228.1-2010, and residual stress measurement references $\mathrm{X}$-ray test method for surface residual stresses of aluminum and aluminum alloys in GB/T 7704-2008 and QJ 2916-97.

First of all, the experimental alloys are completely annealed. The annealing process is carefully warm up and cools down, so as to avoid the introduction of new stress, so that the initial residual stress level of each specimen is the same. The sample size is: $6 \mathrm{~mm} \times 100 \mathrm{~mm} \times 200 \mathrm{~mm}$. Then, in order to preset the stress in the experiments, the residual stress is generated by the way of single direction tension is applied to the samples. Different residual stress of the samples is controlled by controlling different deformation ( $25 \%$ or $50 \%$ deformation). Finally, all the residual stress is measured along the length of the specimen.

\section{Results and Discussion}

Effects of stress relieving annealing on the residual stress. The most important is the temperature $[2,3]$. The residual stress is dependent on temperature due to the plastic deformation or the creep deformation, so the selection of temperature is very important. It is considered that the suitable stress relieving annealing temperature is related to the material composition. It is generally believed that the stress relieving stress is closely related to the creep and stress relaxation.

Fig. 1 shows that the effect of the relieving of the 50\% pre-deformation 5B70 aluminum alloy residual stress at different temperatures.

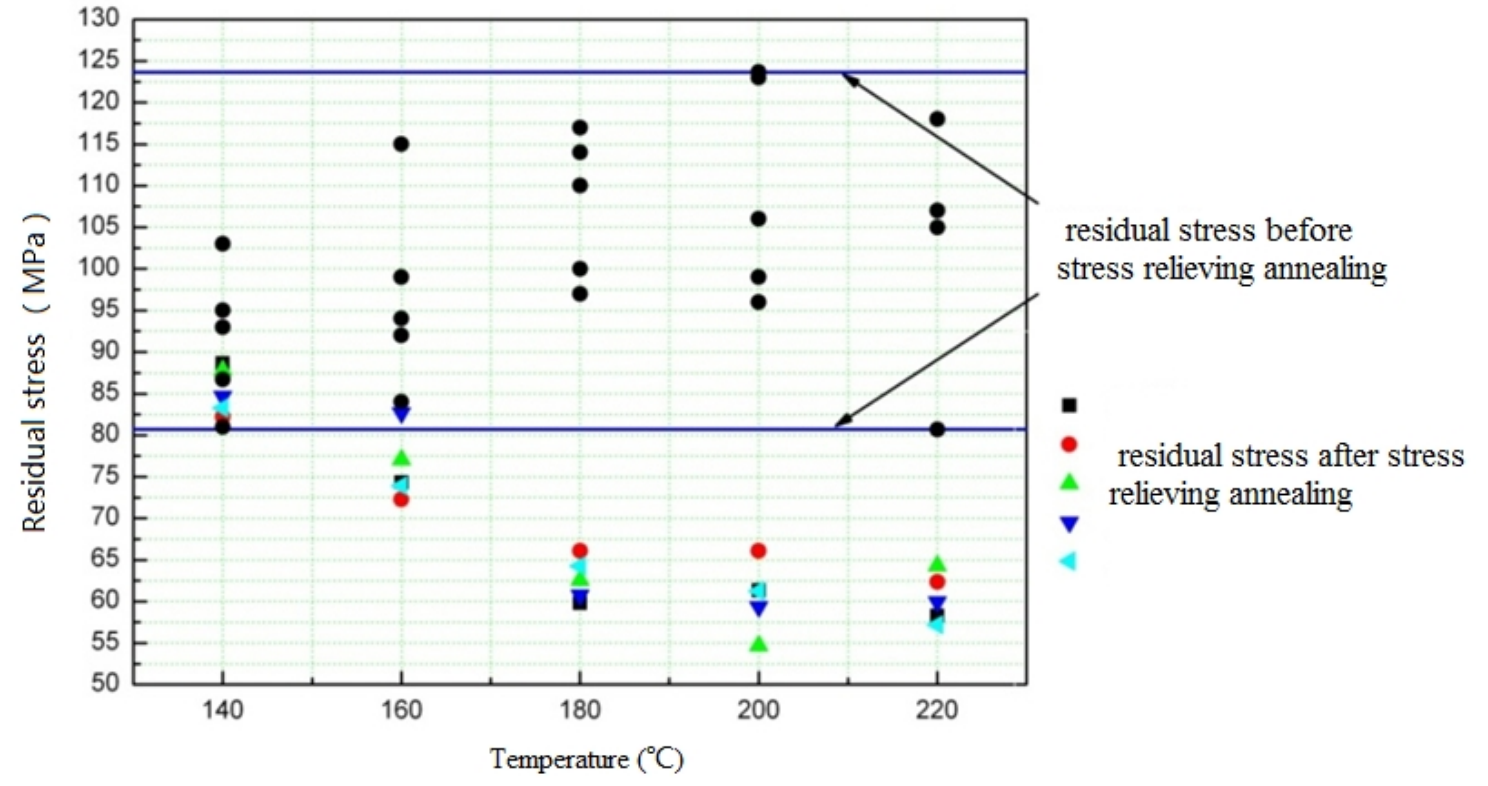

Fig.1 Effects of the residual stress relieving of 5B70 under different stress relieving annealing temperatures

Fig. 1 shows that the residual stress of the samples is greatly decreased after the stress relieving annealing treatment. Under the same annealing time, the residual stress decreases with the increase of the annealing temperature. Over $180^{\circ} \mathrm{C}$, the decrease of the residual stress is little.

On the other hand, when the holding time is different, as shown in Fig.2, at the same temperature, with the extension of the heating time, the residual stress from $0.5 \mathrm{~h}$ to $1 \mathrm{~h}$ is reduced, but the variation is small. The residual stress is reduced due to the recovery of the material. When the annealing time is long enough, the residual stress tends to be stable. The residual stress will not vary significantly even if time continues to extend. From the point of mechanics, it is because when heat energy that the material absorbed runs up to activation energy of most of the residual stress relaxation, the residual stress is released quickly, and the residual stress is gradually slowed down with the increase of holding time. 


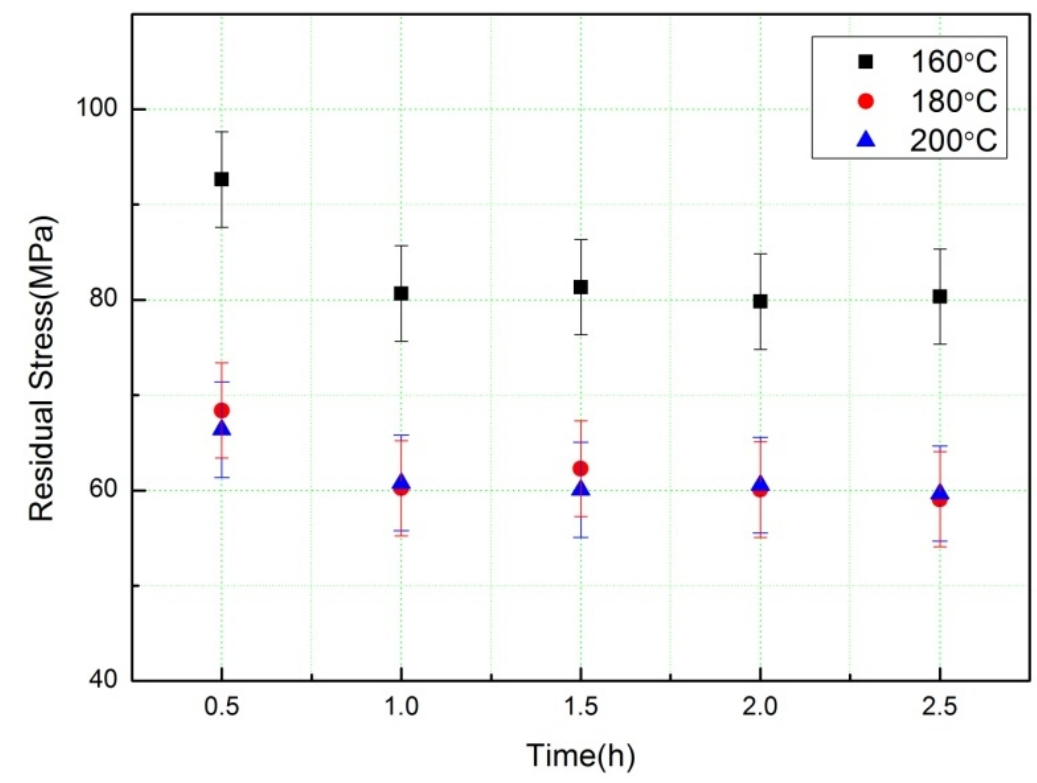

Fig. 2 Relationship between the holding time and the decrease of the residual stress

Then, the decrease of the residual stress of different deformation of the specimen is studied. Stress relieving annealing treatment of 5B70 specimens with different pre deformation amount is carried out, and the residual stress is tested. Fig. 3 shows that the residual stress relieving effect of different pre deformation is much more similar after stress relieving annealing treatment. Therefore, the $5 \mathrm{~B} 70$ alloy, regardless of the amount of the deformation, can choose a stable stress relieving annealing schedule, in order to decrease of the residual stress.

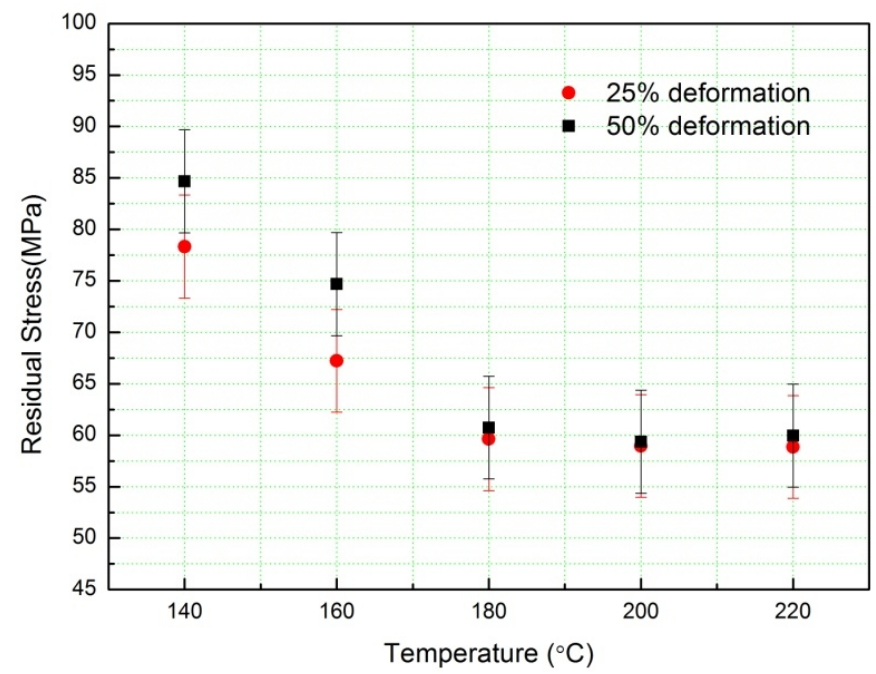

Fig. 3 the decrease of the residual stress of 5B70 with different pre deformation

Finally, the residual stresses of 5A06 and 5B70 were compared after 1 hour stress relieving annealing. According to Fig.4, the trend of the two kinds of materials is consistent after stress relieving annealing, which shows that the formation mechanism of the residual stress of the two kinds of aluminum alloys is similar. 


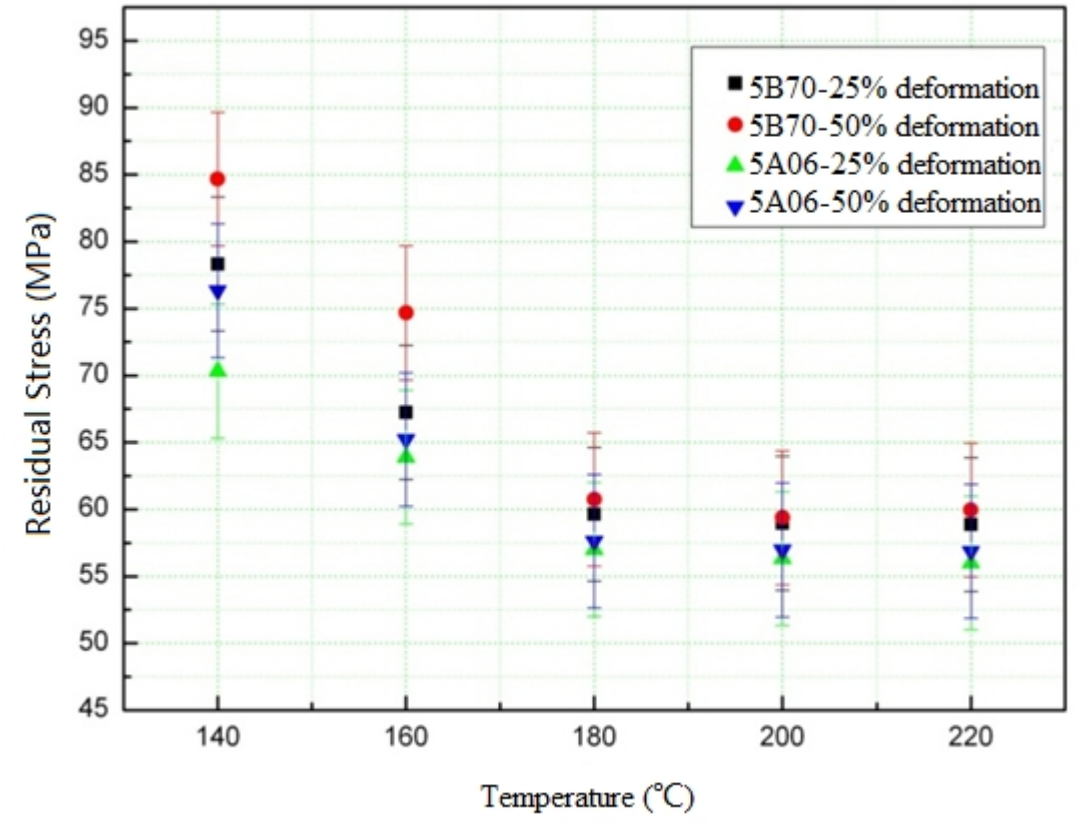

Fig. 4 Comparison of residual stress of 5B70 and 5A06 after stress relieving annealing

Effect of stress relieving annealing on mechanical properties of alloys. First of all, the room temperature strain behavior of 5A06 and 5B70 alloys under different deformation conditions are compared, as shown in Fig.5.This will be used as the base for the mechanical properties of the stress after annealing treatment.

In the influence of deformation amount on the yield strength of the sheet in different degree, the yield strength of 5A06 alloy is improved, but the increase of 5B70 is small. And then in the different degree of deformation of the strain behavior, in comparison with the deformation of $25 \%$ and $50 \%$, we find that the stress and strain behavior of $5 \mathrm{~A} 06$ specimen is uniform strain rate and the increase of strain rate is similar to that of the strain. And by the increase of pre deformation, the elastic stress is increased. But the 5B70 specimen with different degrees of pre deformation has the variable strain rate. when the amount of pre deformation from $25 \%$ to $50 \%$, the elastic strain is slightly decreased.

Therefore, the deformation behavior of 5A06 and 5B70 is different, and the raise of plastic deformation and yield strength of 5B70 under the action of external force is not obviously. The yield strength change is non-linear.
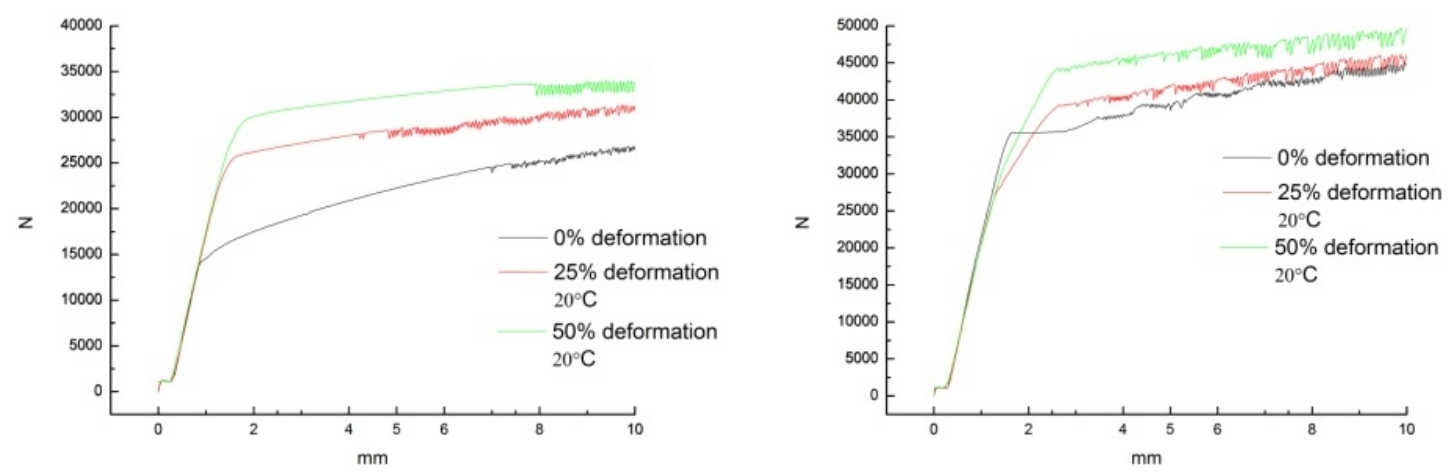

Fig. 5 (a)Stress and strain behavior of 5A06 alloy with different deformation,(b)Stress and strain behavior of 5B70 alloy with different deformation

A reasonable annealing process is not only to consider the complete elimination of stress, but also to take into account the adverse effects of annealing treatment on the performance. Because the material is sensitive to temperature, it is necessary to analyze the mechanism of 5B70 strengthening and avoid the excessive heating temperature, which leads to the deterioration of mechanical performance. 
In general, the A1-Mg alloy is not enhanced by heat treatment. After cold processing and deformation, the internal defect volume fractions of the $\mathrm{A} 1-\mathrm{Mg}$ alloy, the tensile strength and yield strength of the alloy increases.

According to the research of 5B70 alloy, the strengthening mechanism $[4,5]$ of 5B70 includes the following aspects.

1) fine grain strengthening

The addition of trace $\mathrm{Sc}$ and $\mathrm{Zr}$ can refine the grain size of the alloy, which has a strong effect on the grain size of the as cast grains.

2) Sub structure strengthening

In the hot extrusion process of 5B70 alloy, due to the existence of secondary A13 (Sc, Zr) particles, the dislocation substructure formed during the thermal deformation can be retained, and the structure of the alloy is obtained.

3) Precipitation strengthening of A13 (Sc, Zr) particles

In the homogenizing annealing process, the over saturated solid solution will decompose and the fine dispersive secondary A13 (Sc, Zr) particles will separate out from the aluminum alloy, which was added trace $\mathrm{Sc}$ and $\mathrm{Zr}$. These particles and the matrix are in the same crystal lattice, and it can be maintained at the above 550 degree.

The effect of temperature increment on the structure of the organization [5]:

1) In the effect of temperature on the dislocation: Under the status of $\mathrm{H} 32$ of $5 \mathrm{~B} 70$ alloy, cross slip band exists in the microstructure. And dislocation cross slip has left a lot of deformation microstructure in the alloy. With the increase of the annealing temperature, the deformation structure gradually disappeared. After annealing at $200^{\circ} \mathrm{C} / 1 \mathrm{~h}$, the density of dislocation of the alloy is greatly reduced. When the annealing temperature increases to $280^{\circ} \mathrm{C}$, the cross slip band disappears, and the microstructure is obvious.

2) In the aspect of the influence of the temperature on the phase of the material, there are two main forms of Sc in Al-Mg alloy, the primary Al3Sc particles and the secondary A13Sc particles. The former precipitates during solidification process, and the latter precipitates from supersaturated solid solution in the process of annealing. The secondary A13Sc particle can strongly nail grain boundaries and dislocations, effectively organize the migration and consolidation of the sub grain, keep the substructure in stable state, and inhibit the re-crystallization of the alloy. Compared with A13Sc, particle precipitation density increases significantly in the composite of A13 (SC, Zr) phase formed by $\mathrm{SC}, \mathrm{Zr}$. The distribution of the alloy phase in the crystal is more dispersed, but with better ability to inhibit recrystallization.

Therefore, the upper limit of the experimental temperature of 5B70 in the process of stress relieving annealing is $220^{\circ} \mathrm{C}$, and it is better not higher than $200^{\circ} \mathrm{C}$ in practice.

From Fig. 7 and Fig.8, it can be seen that when 5B70 alloys with different pre deformation are placed at temperature range of $140^{\circ} \mathrm{C}$ to $220^{\circ} \mathrm{C}$ for the stress relieving annealing process, the downward trend of tensile strength is very slow; the downward trend of the yield strength is relatively fast.

By the analysis we can know, because of the stress hardening effect of 5B70 alloy, there is a large number of (Sc) particles in the alloy, which has a strong interaction with the A13(Zr) particles. They make the strength of the alloy is very high, but the plasticity is low.

By annealing treatment, the effect of heat activation makes the elastic distortion be released gradually, and the dislocation migrates, and the density of the alloy reduces gradually. At the same time, because of the strong pinning effect of A13 (Sc, Zr) particles and matrix on the dislocation and sub grain boundaries in the alloy, the re-crystallization of the alloy during annealing process is suppressed. The strength of the alloy with stability of the annealing temperature increased slightly decreased, but decrease of tensile strength is not obvious, indicating that 5B70 alloy has high temperature stability by adding Sc. Therefore, the effect of the stress on the microstructure and properties of the 5B70 material is very small, which is less than $220^{\circ} \mathrm{C}$. This is a ideal way to decrease the residual stress. 

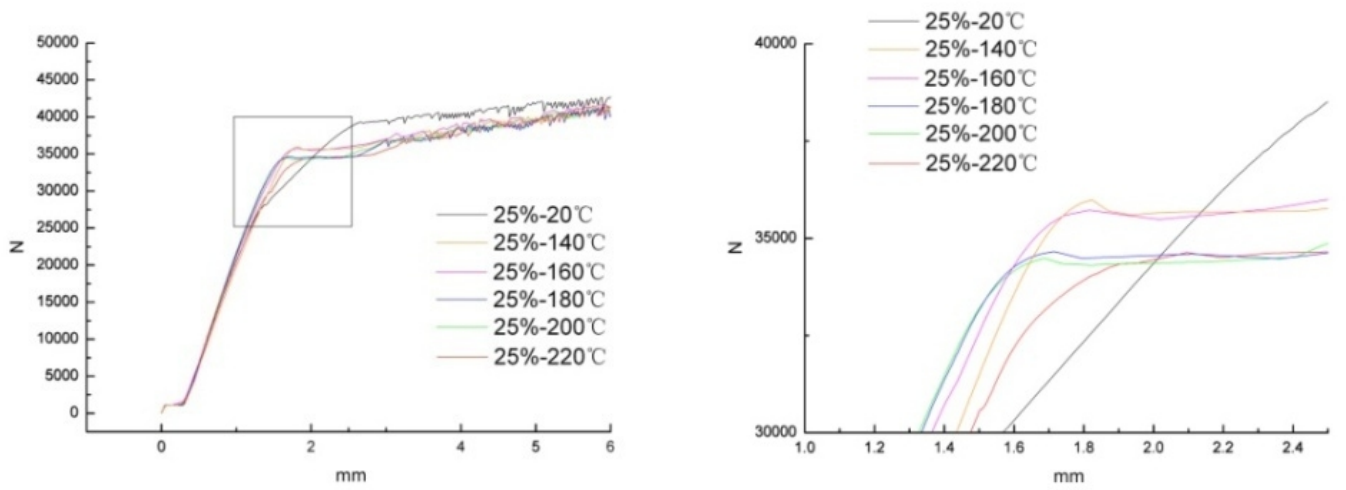

Fig. 6 (a) effect of stress relieving annealing process on the stress and strain behavior of $5 \mathrm{~B} 70$ alloy with $25 \%$ deformation

(b)Stress and strain behavior of the attachment of the yield point
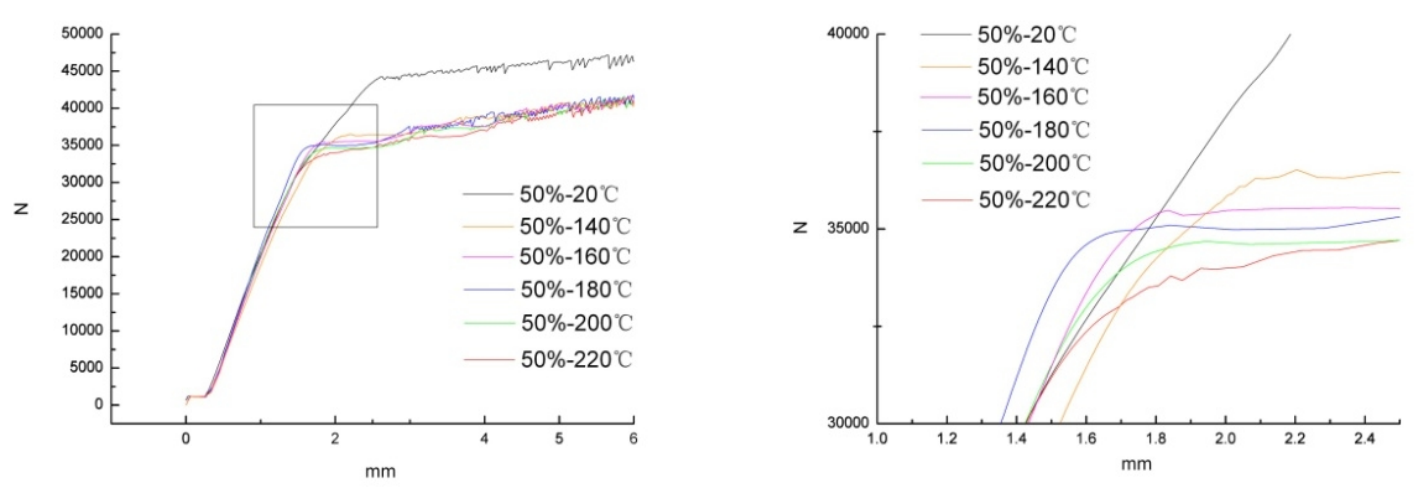

Fig. 7(a) effect of stress relieving annealing process on the stress and strain behavior of 5B70 alloy with 50\% deformation

(b) stress and strain behavior of the attachment of the yield point

By comparison, on the one hand, as shown in Fig.8 and Fig.9, the residual stress after the stress relieving annealing of 5A06 is eliminated, so that the distortion of the alloy can be released, and the strength of the alloy is reduced. On the other hand, according to the previous analysis, the high temperature weakens the dispersion strengthening effect of the alloy. The higher the temperature, the more obvious the trend is. This leads to the decrease of the strength of the alloy with the increase of the annealing temperature.

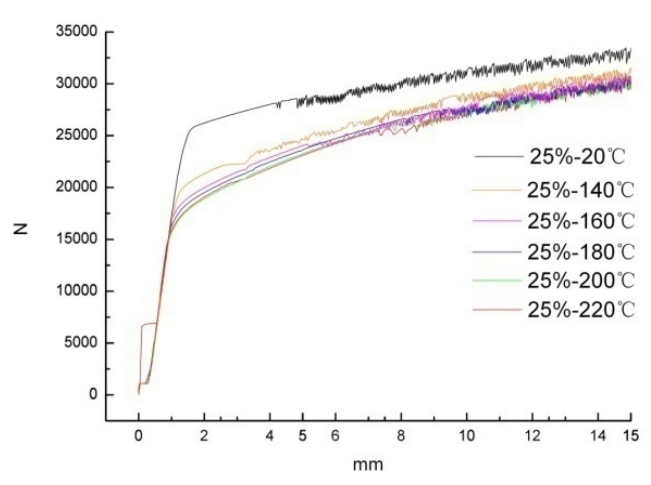

Fig. 8 effect of stress relieving annealing process on the stress and strain behavior of 5A06 alloy with $25 \%$ deformation 


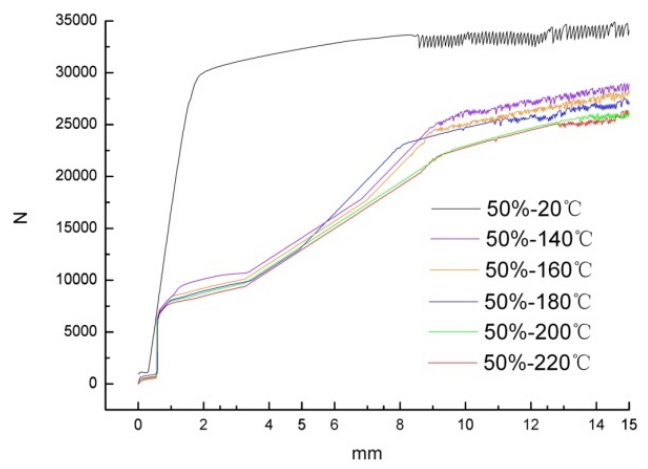

Fig. 9 effect of stress relieving annealing process on the stress and strain behavior of 5A06 alloy with 50\% deformation

\section{Conclusions}

By analyzing the effect of thermal treatment on the residual stress and the mechanical properties of 5B70 alloy by the stress relieving annealing, the stress relieving annealing parameters of 5B70 alloy are "annealing temperature $180 \pm 10^{\circ} \mathrm{C}+$ holding time $60 \mathrm{~min}+$ air cooling". At this time, the yield strength of the material is $290 \sim 300 \mathrm{MPa}$, the tensile strength is $430 \sim 440 \mathrm{Mpa}$, and the elongation is $13 \% \sim 14.5 \%$. The residual stress caused by forming is reduced by $50 \%$.

\section{References}

[1] R V Martins, S Grigull, U Lienert, L Margulies and A Pyzalla,"Investigation of the residual strain state in highly plastically deformed AL - MMC torsion samples using high energy synchrotron radiation", in ICRS-6 Conf Proc, Oxford, United KitIgdom, 10-12 July 2000, v01.1, pp90-97.

[2] D. A. Tanner and J. S. Robinson. Residual stress prediction and determination in 7010 aluminum alloy forgings. Experimental mechanics, 2000, V01. 40, No. 1, pp75-82. [3] M. 1skandar,D. Reyes, Y. Gaxiola. et a1. The effect of varying the solution treatment temperature, natural aging treatment and artificial aging treatment on the mechanical strength of7249 aluminum alloy. Materials Science Forum, 2002, Vols 396-3402, pp 1 121-1 126. [4]Tanner D A, Robinson J S. The magnitude of heat treatment induced residual stresses and the thermal stress relief of aluminum alloys. Materials science forum, 2002, Vols404-407, pp355-360.

[5]Michael B Prime. Quenching and cold-work residual stresses in aluminum hand forgings: Contour method measurement and FEM prediction. Material Science Forum, 2003, Vols. 426 — 432, PP. 435-440. 